\title{
Self-Care Practice of Community Dwelling Diabetic Elders
}

\author{
Somaya El-Shazly*, Nahed Mohamed Saied Ayoub**, Hanaa Shafic*
}

\begin{abstract}
Diabetes is common chronic disease encountered by individuals in late life. Diabetes and its complications can impaire well being and quality of life of elders. Patient's compliance and self-care practices are critical facors in appropriate management of diabetes mellitus. So, this study aimed at identifying self-care practice of community dwelling elders. The study sample comprises 105 diabetic elderly who attending the outpatient diabetic clinic at Farouk Hospital, which is affiliated to Ministry of Health and Population. The study revealed that the majority, of the studied diabetic elders had a poor adherence to self-care practice. It was found that self-care practices are affected by sex, marital status, and income of the elders. Also, self-care practice had a significant relation with fasting blood level, body mass index, and the number of foot problems. Knowledge of diabetic elders is essential for self-care practice which is affected by elders' educational level. The study recommended that encouraging elders' independency, and providing financial and social supports are an essential part for self-care practices
\end{abstract}

\section{INTRODUCTION}

Diabetes Mellitus (DM) is a common clinical and public health problem affecting individuals in late life. In USA, $20 \%$ of individuals aged 65 years or more have either diagnosed or undiagnosed diabetes mellitus. (1) In Europe, the prevalence rate of DM was $3-10 \%$. Higher rate $14-20 \%$ is reported in Indian, Chinese, and Hispanic American population.(2) In Egypt, the total prevalence of diagnosed diabetes is $4.3 \%$ with district geographic differences, 5.7\% in urban areas, $4.1 \%$ in rural agricultural parts, and $1.5 \%$ in rural desert areas. ${ }^{(3)}$ In Alexandria, it was estimated that the prevalence is as high as $5 \%$ of the total population. ${ }^{(4)}$

Diabetes mellitus is defined as a disorder characterized by chronic hyperglycemia resulting from defects in insulin secretion, insulin action or both.(5) There are several

\footnotetext{
* Gerontological Nursing, Faculty of Nursing Alexandria University

** Gerontological Nursing, Faculty of Nursing El-Mansoura University
} 
types of Diabetes Mellitus: Adult-onset mellitus as polyuria, polydepsia, and diabetes or non-insulin dependent diabetes polyphagia, but manifest the disease mellitus (NIDDM) which occurs with atypically in the form of incontinence, increased frequency in elderly persons. dehydration, confusion, blurred vision, Type II diabetes may go undiagnosed for chronic infection, poor wound healing, and elders. This may be due to age related heart disease which are considered changes and the atypical manifestations of complications of the disease. These factors the disease. Age-related changes include combined with obesity, lack of activity and decrease in the function of beta cells of the loss of muscle mass, which are common pancreas which leads to less insulin among elders, put them at risk to develop secreted, and the presence of insulinopenia hyperglycemia slowly and may not be resulting from insulin resistance in the severe enough to cause noticeable number of insulin receptors sites. Also to symptoms. ${ }^{(5,6)}$

changes in the urinary system which include reduction in filtration rate, blood supply to the kidneys, and increase the renal threshold up to $180 \mathrm{mg} / \mathrm{dl} .{ }^{(6)}$

Another factor that contributes to undiagnosed diabetes mellitus is the absence of typical manifestations of the disease. Elderly patients may not report the classical signs and symptoms of diabetes

Diabetes with long term duration may cause short or long term complications. Short term involves diabetic ketosis, hypo and hyperglycemia, Infection, and hyperosmolar non-ketotic state. While, long term complications include micro and macro vascular complications, such as retinopathy, nephropathy, cardiovascular, peripheral, and cerebral diseases. ${ }^{(7)} \quad$ Most of 
these complications result from high blood sugar level. These complications may affect the ability of elderly persons to perform activities of daily living, instrumental activities of daily living and self-care and may accelerate dependency and increase the need for multiple services with its associated economic consequences. ${ }^{(8,9)}$ Controlling blood sugar level, short, and long term complications can be minimized leading to high quality of life. In Philadelphia, there is evidence from large studies that improved glucose control in type II diabetes mellitus reduces the risk of development and progression of complications especially micro and macro complications. ${ }^{(10)}$

The success of diabetes management depends on the patient's compliance with the prescribed management plan. (3) In Alexandria, a study conducted in elderly homes reported that the majority of elders were non-complying with their medications regardless of the diagnosis. ${ }^{(11)}$ Another study carried out in the out patient diabetic clinic for elders stated that most of elders were non- complying with their atment regimen $^{(12)}$

Therapy for diabetes mellitus focuses on diet, exercise, hygiene, and insulin or oral blood glucose lowering agents. Also, bathing, personal hygiene, oral care, skin care, frequent foot examination, and preventive foot care are important. ${ }^{(13)}$

Enhancing self-care capacity can help in achieving the optimal level of compliance with diabetes mellitus therapy.

Self-care is the ability of a person to meet his demands. Diabetes self-care comprises either strict adherence to the prescribed regimen or active self-care. Strict adherence is the level to which the patient daily follows the diabetes self-care regimen. While active self-care means self 
monitoring, dietary adjustment, insulin Hospital for a period of three months and dosage, and regular exercise. ${ }^{(14)}$

fulfilled the following criteria:

Gerontological nurse has an important - age 60 years and above, diagnosed with role in assessing the self-care practice of diabetes for not less than one year diabetic home bound elders, as an essential and willing to participate in the study. Their aspect of holistic care provided to the elders for healthy aging.

number amounted to 105 elders.

Tools of data collection:

\section{Aim of the study:}

In order to collect the necessary

The aim of this study was to identify self- information, the following tools were used: care practice of community dwelling diabetic elders.

\section{Tool I:}

A structured interview schedule: It was

\section{MATERIAL AND METHODS}

\section{Design:}

Descriptive study.

\section{Setting:}

The study was conducted in outpatient diabetic clinic at Farouk Hospital, which is affiliated to Ministry of Health and Population.

\section{Subjects:}

The sample comprised all elders attending the diabetic out patient clinic at Farouk developed based on review of recent literatures. It included the following information related to:

1- Socio-demographic characteristics of the elderly such as age, sex, marital status, level of education, income, and its source.

2- Medical history: type of other chronic diseases and the type of medication used.

3- History of diabetes: duration of diabetes and medications used. 
4- Family history.

5- Self-care activities which included information related to drug intake, diabetic diet, exercise, blood glucose analysis, and periodic check up.

\section{Tool II:}

An assessment sheet: This sheet was developed by the researchers and included items related to:

a- Mouth condition

b- Skin condition

c- Foot condition

d- Measuring fasting blood sugar

e- Measurement of body weight and height

\section{Method:}

1- Tool I and tool II were developed by the researchers after thorough reviewing of literature.

2- A Pilot study was performed on 10 elderly in the same setting, and not included in the sample. It was done to assess clarity and applicability of the tools. Result of this study revealed that all tools were clear, applicable and no changes or exclusion of item were done.

3- A verbal consent of elderly person to participate in the study was obtained after explanation of the study purpose.

4- Every patient was interviewed individually to collect the necessary information. The interview took about 30-45 minutes.

5- Each patient was examined to assess mouth, skin, and foot condition for any abnormalities. Also, the height and weight of patient were measured.

6- Data were collected over a period of three months starting from August till the end of September 2006.

\section{Statistical Analysis}

Data were analyzed using SPSS software version 13.0. Descriptive statistics as proportion, mean, and standard deviation were used. Categorical variables were contrasted by Pearson chi-square or chisquare for trend. In case of small cell 
frequency, the $p$ value for chi-square is knowledge score was 13 . They were divided replaced by Fisher's exact $\mathrm{p}$ or Monte Carlo into the following levels:

exact p. Ordinal variables were tested for Good $=>75 \%$ of the correct answers

correlation by Spearman correlation Fair $=50-75 \%$ of the correct answers

coefficient or Kendall's tau-b. All reported $p$ Poor $=<50 \%$ of the correct answers

values are two-tailed. The level of RESULTS

significance was set at 0.05 .

Table 1 shows the socio- demographic

To determine the body mass index characteristics of the diabetic elderly (BMI) the following formula was used

$\mathrm{BMI}=$ weight in $\mathrm{kg} . \div{\text { (height in meters })^{2}}^{2}$ patients. The sample aged $60-84$ years with a mean age of $\quad(72.1 \pm 4.54$ years $)$. Most The calculated BMI were compared with reference to identify underweight and overweight elderly patients

- $\quad \leq 22.0 \mathrm{~kg} / \mathrm{cm}^{2}$ (underweight)

- $\quad 22.0-27.0 \mathrm{~kg} / \mathrm{cm}^{2}$ (normal weight)

- $\quad \geq 27.0 \mathrm{~kg} / \mathrm{cm}^{2}$ (over weight)

- $\quad \geq 30.0 \mathrm{~kg} / \mathrm{cm}^{2}$ (obesity) $^{(15)}$

-The diabetic elderly knowledge and selfcare practice were calculated for all areas of diabetic regimen as follows:

Correct answer was scored one and incorrect was zero. The total self-care practice score was 34 and the total of the sample was females (61\%), $37.1 \%$ were illiterate, and those with basic education or secondary school education were represented by $20.9 \%$ and $19 \%$, respectively, those who completed their university education were $12.4 \%$. As regards the marital status of the sample, it was observed that $40.0 \%$ were married, $39.0 \%$ were widowed, $18.1 \%$ and $2.9 \%$ were either single or divorced, respectively. More than one-third of the elders were either employee or manual worker (44.8\% and $43.8 \%$, respectively). Regarding the 
income of the elderly, it ranges from $70-350$

LE/month with a mean $220.48 \pm 120.83$ LE. Nearly half of elders (43.8\%) had limited income $<200 \mathrm{LE} /$ month and the main source of income reported by the majority of elders $(85.8 \%)$ was pension.

Table 2 demonstrates the medical history and medication used by the diabetic elderly. Regarding the medicalhistory, cardiovascular diseases and gastrointestinal diseases were the most frequent diseases reported by the diabetic elderly patients (60.9\% and 49.4\%, respectively), while $42.9 \%$ of the sample had positive family history of diabetes mellitus. Concerning the duration of diseases, the table shows that the majority of the sample $(82.8 \%)$ had diabetes for a period of five years and more and nearly two-thirds of them use oral hypoglycemic drug (66.7\%). While only $4.8 \%$ use a combination of oral hypoglycemic drugs and insulin.
Table 3 illustrates the distribution of the diabetic elders according to their mouth, and foot problems. Concerning mouth condition it was observed that teeth problems as missing teeth, teeth decay, lose teeth, and wearing denture are observed in $84 \%$ of the patients, followed by gum problems as gum sores, bleeding, and swelling which was observed in $42 \%$ of elders, and fissure of lips was observed in $16.2 \%$ of the elders. Regarding the feet problems in the diabetic elders, it was observed that $90.5 \%$ of the sample had dry skin, while feet edema was observed at $44.8 \%$ of the elders followed by abnormal color of the feet (27.7\%) such as redness, pale, and cyanosis. $19.1 \%$ of the elders had impaired skin integrity, and $1.9 \%$ had absent pulse. Nail problems (ingrowing nails, cyanosis, and corns) were found in $13.4 \%$ of the elders.

Table 4 illustrates the fasting blood glucose (FBG) level, and body mass index (BMI) of the diabetic elders in relation to the 
age, sex, and duration of disease. The table demonstrates that fasting blood sugar and body mass index were not affected significantly by age, sex, and duration of the disease.

Table 5 shows the level of knowledge and self-care practices of diabetic elders in relation to their socio-demographic characteristics and health condition. Regarding the knowledge of diabetic elders, the table shows that $81 \%$ of the sample had fair knowledge and only $1.9 \%$ had good knowledge. There is no statistical significant difference in relation of socio-demographic characteristics and health condition and level of knowledge. While the educational level had significant effect on level of knowledge $(p=0.028)$. Concerning self-care practices of diabetic elders in relation to their socio-demographic characteristics and health condition the table shows that $39 \%$ of the elders had poor practice, while fair practice was represented by $41 \%$, and $20 \%$ had good practice. There is a statistical significant difference between sex, marital status, educational level, monthly income, and type of hypoglycemic drug used and practices.

Table 6 shows the relation between level of knowledge, self-care practices and blood sugar level, caloric intake, and fluid intake. Regarding fair knowledge $50 \%$ of the patients had high blood sugar level, and $39.5 \%$ of fair knowledge are overweight, $12.8 \%$ of them received more than daily caloric requirement, and $90.7 \%$ received $<2000 \mathrm{ml} /$ day. Concerning the practices level, $66.7 \%$ of elderly who had good practice had a normal blood sugar, while $71.4 \%$ of good practice were overweight, and $81 \%$ of them received less than the daily caloric requirement, and $95.2 \%$ received inadequate fluid intake. The table denoted that there is no significant statistical relation between level of knowledge, selfcare practice and blood sugar level, body 
mass index, daily caloric requirement, and amount of fluid intake/day.

Table 7 shows the number of mouth, skin, and foot problems in relation to elderly diabetic patient's level of knowledge and self-care practices. There is a significant relation between level of knowledge, selfcare practices, and number of feet problem $(p=0.002$ and 0.046 , respectively). While, this relation was not noted in relation to number of mouth problems $(p=0.914$ and 0.443 , respectively.)

\section{DISCUSSION}

Diabetes Mellitus is a chronic illness that requires continuing medical care and education. Elders' compliance and self-care are critical factors in appropriate management of diabetes mellitus. ${ }^{(16)}$ Nursing care for diabetic elders achieves its objectives when it enables the elders to reach an optimal level of independence based on elders' needs. Accordingly, gerontological nurse can not successfully plan self-care interventions until identifying diabetic patients' self- care practices, needs, and investigate barriers to these practices. So, this study aimed at determining selfcare practices of community dwelling diabetic elders.

Active self-care refers to self monitoring, dietary adjustments, insulin dosage for daily purposes and regular exercise. ${ }^{(14)}$ The present study revealed that the majority of elders had either poor or fair self-care practice. This is in accordance with other study about self-care practice among home based diabetic elders in Dakahlia Governorate.(2)

Effective self-care practice is affected by many factors as physical, mental and socio-economic abilities of elders. Also, knowledge of elders and the ability to take decision are two factors that should be considered in assessing self-care practice of elders. ${ }^{(17)}$ This supports the results of the present study which revealed that marital 
condition, sex, education, and income of the elders had a significant effect on elders' self-care practices (Table 5).

Chronic morbidities may induce dependency in activities of daily living (ADL) and increase the risk for complications. Cardiovascular diseases are the most chronic diseases affecting diabetic elders (table 2). This is supported by other studies conducted in elderly homes in Alexandria-(18-20)

Concerning health condition of diabetic elders, the present findings stated that the majority of elders had poor mouth condition (table 3). This result was supported by Amer et al., and Heggy who reported an association between diabetes mellitus and pathologic changes. ${ }^{(21,22)}$

In relation to foot problems, most of diabetic elders had dry skin which is considered a risk factor for foot ulcer followed by presence of edema which was reported by more than one-third of elders (table 3 ). These problems may be considered by diabetic elders as normal part of aging process. So, elders may be less adherent to skin and foot care. Abdel-Rehim and Eweda et al., added that complications in diabetes mellitus usually result from a triad of peripheral neuropathy, peripheral vascular insufficiency, and infection. (23,24).

Body mass index (BMI) appears to be a widely accepted index for classifying adiposity in elders, where BMI above $27 \mathrm{~kg} / \mathrm{m}^{2}$ is used as a scoring index for overweight and above $30 \mathrm{~kg} / \mathrm{m}^{2}$ as an index of excess obesity. ${ }^{(15)}$ The results of the present study revealed that more than onethird of elders were overweight and approximately one-third are obese. Obesity and overweight had no significant relation with age, sex, or duration of disease. While, body mass index had a significant relation with self-care practice (table 6). This is in accordance with two studies conducted in Kwait and India.

Glucose level is vital sign to individual with 
diabetes mellitus. It is important to maintain blood sugar levels within a normal range to avoid short and long term complications. More than half of the elders had high fasting blood sugar (table 6). This clearly reflects the non-compliance of elders with the prescribed diabetic regimen. The results of the present study are supported by another study conducted in diabetic out patient clinics for elders which stated that the majority of elders were non complying with their prescribed drugs. ${ }^{(12)}$

Knowledge about diabetic care is essential. Learning much about diabetes and its management can improve self-care practice. ${ }^{(10)}$ In the present study, it was reported that the majority of diabetic elders $(81.9 \%)$ had fair knowledge about diabetes. Knowledge had a significant relation with the occurrence of foot problems which is considered as part of self-care practice. This result is in accordance with other study conducted in Finland which stated that lack of knowledge affected the adherence to selfcare practice. ${ }^{(14)}$ Improving elders' knowledge of diabetic self-care practices will allow them to be able to manage diabetes effectively.

Self-care practice had a significant relation with the occurrence of foot problems, body mass index and blood glucose level. Poor self-care causing poor long term metabolic control, which may lead to the development of diabetic complications. Patient's self-care practices are a very crucial part of maintaining a good diabetes status.

\section{CONCLUSION}

It can be concluded from the study that the majority of the community dwelling diabetic elders had a poor adherence to self-care practice.

Self-care practices are affected by sex, marital status, and income of the elders. Also, self-care practice had a significant relation with fasting blood level, body mass 
index, and the number of foot problems. 1- Financial and social supports are Knowledge of diabetic elders is affected by essential for improving self-care elders' educational level. practices.

\section{RECOMMENDATION}

2- Mass Media can assist in providing the

The following recommendations are diabetic elders with essential information suggested:

1. Encourage elders' independency is an essential part for self-care practices. about the diseases process, complications, and its management which help to increase self-care practice of diabetic elders. 
Table1: Socio-demographic characteristics of diabetic elderly

\begin{tabular}{|c|c|c|}
\hline \multirow[t]{2}{*}{ Socio - demographic Data } & \multicolumn{2}{|c|}{$n=105$} \\
\hline & No. & $\%$ \\
\hline Age in years: & & \\
\hline $60-$ & 85 & 80.9 \\
\hline $75-$ & 20 & 19.1 \\
\hline $85+$ & 0 & 0 \\
\hline Mean \pm SD & \multicolumn{2}{|c|}{$72.10 \pm 4.54$} \\
\hline $\begin{array}{l}\text { Sex: } \\
\text { Male }\end{array}$ & 41 & 39.0 \\
\hline Female & 64 & 61.0 \\
\hline $\begin{array}{l}\text { Marital Status: } \\
\text { Married }\end{array}$ & 42 & 40.0 \\
\hline Widowed & 41 & 39.0 \\
\hline Single & 19 & 18.1 \\
\hline Divorced & 3 & 2.9 \\
\hline $\begin{array}{l}\text { Educational Level: } \\
\text { Illiterate }\end{array}$ & 39 & 37.1 \\
\hline Basic education & 22 & 20.9 \\
\hline Secondary school & 20 & 19.0 \\
\hline University & 13 & 12.4 \\
\hline Read and write & 11 & 10.5 \\
\hline \multicolumn{3}{|l|}{ Occupation before retirement: } \\
\hline Employee & 47 & 44.8 \\
\hline Manual work & 46 & 43.8 \\
\hline House wife & 8 & 7.6 \\
\hline Seller & 4 & 3.8 \\
\hline $\begin{array}{l}\text { Income: } \\
<200 \text { L.E }\end{array}$ & 46 & 43.8 \\
\hline $200-$ & 19 & 18.1 \\
\hline $300+$ & 40 & 38.1 \\
\hline Mean \pm SD & \multicolumn{2}{|c|}{$220.48 \pm 120.83$} \\
\hline Source of income: & & \\
\hline Pension & 90 & 85.8 \\
\hline Son/daughter & 9 & 8.6 \\
\hline Friends/relatives & 4 & 3.8 \\
\hline Social assistance & 2 & 1.8 \\
\hline
\end{tabular}


Table 2: Medical history and medication used by the diabetic elderly

\begin{tabular}{|c|c|c|}
\hline Health status & \multicolumn{2}{|c|}{$\mathrm{n}=\mathbf{1 0 5}$} \\
\hline & No. & $\%$ \\
\hline \multicolumn{3}{|l|}{ Medical History\# } \\
\hline Cardiovascular diseases & 58 & 60.9 \\
\hline Gastrointestinal diseases & 47 & 49.4 \\
\hline Musculoskeletal diseases & 16 & 15.2 \\
\hline Others & 5 & 4.9 \\
\hline None & 23 & 21.9 \\
\hline $\begin{array}{l}\text { Family history of Diabetes } \\
\text { yes }\end{array}$ & 45 & 42.9 \\
\hline No & 70 & 57.1 \\
\hline \multicolumn{3}{|l|}{ Onset of diabetes by years } \\
\hline $1-$ & 5 & 4.8 \\
\hline $3-$ & 13 & 12.4 \\
\hline $5+$ & 87 & 82.8 \\
\hline Mean \pm SD & \multicolumn{2}{|c|}{$5.56 \pm 1.04$} \\
\hline $\begin{array}{l}\text { Hypoglycemic drugs used } \\
\text { Oral Hypoglycemic drugs }\end{array}$ & 70 & 66.7 \\
\hline Insulin & 30 & 28.6 \\
\hline Oral Hypoglycemic drugs \& insulin & 5 & 4.8 \\
\hline
\end{tabular}

\# More than one answer were given

Table 3: Distribution of the diabetic elders according to their mouth, and foot problems

\begin{tabular}{|c|c|c|}
\hline \multirow{2}{*}{ problems } & \multicolumn{2}{|c|}{$\mathbf{n = 1 0 5}$} \\
\cline { 2 - 3 } & No. & $\%$ \\
\hline Mouth problems: \# & & \\
\hline Teeth & 88 & 84 \\
\hline gum & 44 & 42 \\
\hline Fissure of lips & 17 & 16.2 \\
\hline Feet problems\# & & \\
\hline Dryness of the skin & 99 & 90.5 \\
\hline Edema & 47 & 44.8 \\
\hline Abnormal color & 28 & 27.7 \\
\hline Impaired skin integrity & 19 & 19.1 \\
\hline Coldness of feet & 6 & 5.7 \\
\hline Nail problems (Ingrowing & 12 & 13.4 \\
\hline corns, cyanosed nails & & \\
\hline Absent pulse & 2 & 1.9 \\
\hline nails, & & \\
\hline mmore than one answer & & \\
\hline & & \\
\hline
\end{tabular}

\#more than one answer 


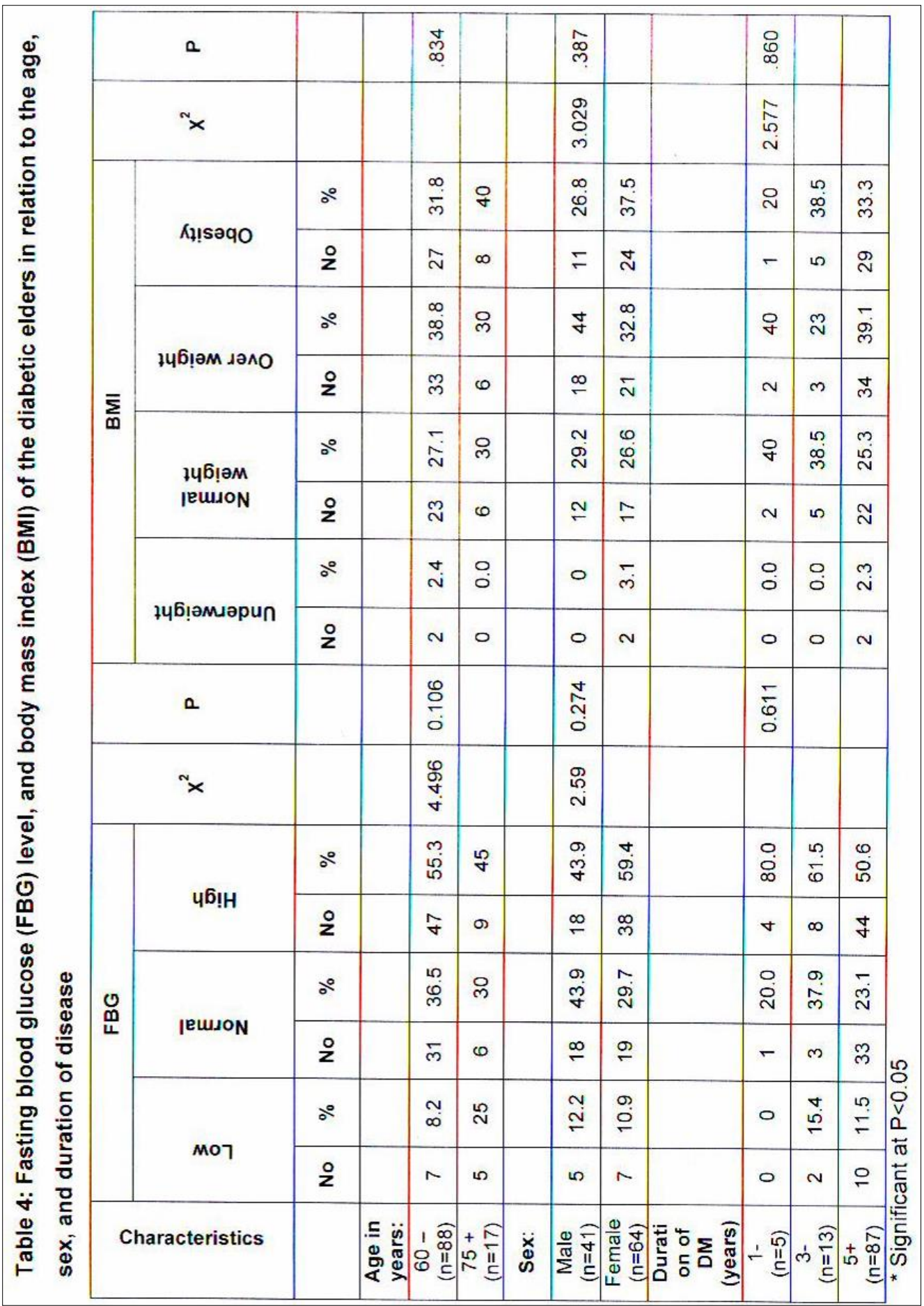




\begin{tabular}{|c|c|c|c|c|c|c|c|c|c|c|c|c|c|c|c|c|c|c|c|c|c|}
\hline 0 & : & 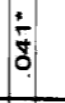 & \%ั. & & & & : & & & & & ?ֶ. & & & ס̊ & & . & 8 & & & \\
\hline & & $\stackrel{n}{8}$ & $\ddot{0}$ & $\stackrel{\leftrightarrow}{9}$ & $\begin{array}{l}\frac{\pi}{4} \\
\frac{\pi}{4}\end{array}$ & 0 & $\hat{N}$ & $\because$ & 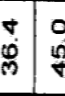 & $\begin{array}{ll}0 \\
6 \\
+ & 1\end{array}$ & $\stackrel{\circ}{\wedge}$ & \begin{tabular}{l|l}
0 & + \\
$\stackrel{\rho}{*}$
\end{tabular} & $\stackrel{\infty}{\stackrel{N}{\sim}}$ & $\begin{array}{l}0 \\
0 \\
0\end{array}$ & \begin{tabular}{l|l}
$n$ & $\bar{v}$ \\
0 & $\mathrm{~N}$
\end{tabular} & $\begin{array}{l}0 \\
\vdots \\
n\end{array}$ & $0 \mathrm{~N}$ & 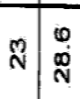 & 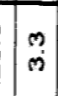 & & กิ \\
\hline & $\infty$ & $0:$ & o & $\infty$ & $\infty$ & 0 & $m$ & 0 & $\infty$ & o & - & $\sigma$ & - & 0 & $\infty \mid \infty$ & $\div$ & $0-2$ & ล & $r$ & & $\bar{N}$ \\
\hline . & $\left|\begin{array}{c}0 \\
0 \\
0 \\
0 \\
0\end{array}\right|: 0$ & & 㐫 & 免 & $\overline{\mathrm{N}}$ & \begin{tabular}{|l|} 
\\
$\dot{g}$ \\
$\dot{g}$ \\
$口$
\end{tabular} & $\begin{array}{l}n \\
\infty \\
m\end{array}$ & $\stackrel{?}{\text { N }}$ & $\begin{array}{l}\text { ه } \\
\dot{q}\end{array}$ & $\dot{0}: \hat{8}$ & 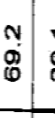 & j & $\begin{array}{l}0 \\
\qquad \\
2\end{array}$ & $\begin{array}{l}0 \\
0 \\
0\end{array}$ & 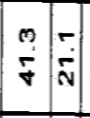 & 0 & $\rightarrow \frac{n}{6}$ & 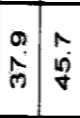 & $\stackrel{m}{m}$ & : & $\frac{4}{4}$ \\
\hline & & $N 2$ & $\stackrel{6}{2}$ & i & 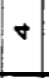 & $m$ & $\stackrel{n}{=}$ & $m$ & क & 10 & 0 & $\bar{n}$ & $N$ & $N$ & 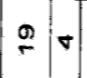 & is & $\mathrm{N}:$ & है & N & & g \\
\hline & $\stackrel{\mathbb{Z}}{\mathbb{4}}$ & & तु & $\frac{\hat{n}}{\bar{n}}$ & $\begin{array}{l}0 \\
\dot{m} \\
\end{array}$ & $\begin{array}{l}0 \\
0 \\
0\end{array}$ & $\begin{array}{ll}\infty & 1 \\
8 & 8\end{array}$ & $\begin{array}{ll}\hat{\mathrm{N}} & \hat{\Omega}\end{array}$ & \begin{tabular}{l|l}
$\hat{\mathrm{N}}$ & 0 \\
0
\end{tabular} & 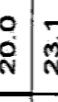 & $\begin{array}{c}\bar{c} \\
\bar{n}\end{array}$ & \begin{tabular}{l|l}
$m$ & 0 \\
$\dot{v}$ & $\frac{m}{m}$
\end{tabular} & $\begin{array}{l}0 \\
\tilde{\sigma} \\
0\end{array}$ & $\begin{array}{l}0 \\
\dot{0} \\
0\end{array}$ & 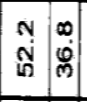 & 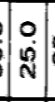 & : & $\bar{g}$ & $\vec{R}$ & $\stackrel{\sim}{\circ}$ & (8) \\
\hline & $\stackrel{m}{m}$ & N & N & $m$ & 0 & 0 & $\bar{N}$ & $\infty$ & $n$ & $\nabla m$ & m & $\stackrel{2}{2}$ & in & N & $\Delta$ & $\div$ & $\infty>$ & $\vec{m} \stackrel{\infty}{\sim}$ & $\mathbb{N}$ & & $=$ \\
\hline 0 & . & : & 哭 & & & & & & & & & ถู & & & ผै & & 离 & 员 & & & \\
\hline & & ه: & $\stackrel{\Delta}{\mathrm{N}}$ & $\stackrel{\dot{H}}{\mathrm{~N}}$ & $\begin{array}{l}0 \\
0\end{array}$ & $\begin{array}{l}0 \\
\dot{0}\end{array}$ & $\stackrel{\circ}{\circ}$ & $\begin{array}{lll}\circ & 0 \\
\dot{0} & 0\end{array}$ & $\begin{array}{ll}\circ \\
\circ\end{array}$ & $\begin{array}{ll}0 & 0 \\
0 & 0\end{array}$ & o & \begin{tabular}{l|l} 
N & $\dot{\mathrm{N}}$
\end{tabular} & $\begin{array}{l}0 \\
0\end{array}$ & $\begin{array}{l}0 \\
0\end{array}$ & \begin{tabular}{l|l|}
0 & 0 \\
0 & 0
\end{tabular} & $\left|\begin{array}{l}0 \\
10\end{array}\right|$ & 0.0 & $\stackrel{m}{\mathrm{~N}} \stackrel{+}{-}$ & $=0 \begin{array}{l}n \\
0\end{array}$ & 0 & هُ \\
\hline & & No & $r$ & 5 & 0 & 0 & 0 & 0 & 0 & $\mathrm{~N} 10$ & 0 & $r$ & 0 & 0 & 0.0 & $\mathbf{N}$ & 0 & N - & - & 0. & $N$ \\
\hline 语 & 9 & 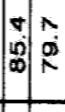 & $\begin{array}{l}N \\
0 \\
R\end{array}$ & $\begin{array}{l}\infty \\
0 \\
0\end{array} \mid$ & $\begin{array}{c}N \\
\dot{w} \\
\infty\end{array}$ & $\begin{array}{l}\hat{0} \\
\dot{8}\end{array}$ & $\begin{array}{ll}0 \\
\dot{\Phi} \\
\infty\end{array}$ & 苟 & $\begin{array}{lll}\infty & 0 \\
-\infty & 0 \\
\alpha & 0\end{array}$ & & 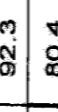 & \begin{tabular}{lll}
$\forall$ & 9 \\
\hdashline & 0 \\
\hdashline & 0
\end{tabular} & $\begin{array}{l}0 \\
\hat{D} \\
\infty\end{array}$ & $\begin{array}{l}0 \\
0 \\
0\end{array}$ & \begin{tabular}{l|l} 
& 0 \\
$\dot{D}$ & 0 \\
\hdashline & 0 \\
\end{tabular} & 足 & 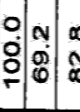 & \begin{tabular}{c|c}
$\infty$ \\
$\underset{\infty}{\infty}$ \\
$\underset{\infty}{\mathbb{N}}$
\end{tabular} & \begin{tabular}{|l|l|} 
& $\kappa$ \\
$\dot{j}$ & $\stackrel{0}{*}$
\end{tabular} & $\begin{array}{l}0 \\
8 \\
0\end{array}$ & $\left|\begin{array}{c}0 \\
\frac{1}{\infty}\end{array}\right|$ \\
\hline & & (n) & है & है & $\stackrel{9}{\circ}$ & N & $\begin{array}{ll}9 \\
m\end{array}$ & 0 & $\stackrel{\infty}{\leftarrow}$ & $\Rightarrow \because$ & $\stackrel{N}{\sim}$ & क् & $\wedge$ & t & $\hat{m}: \stackrel{n}{\square}$ & ले & का & \begin{tabular}{l|l}
$N$ & $\infty$ \\
$\sim$
\end{tabular} & $: \mathbb{N}$ & 0 & $\left|\begin{array}{l}0 \\
\infty\end{array}\right|$ \\
\hline $0^{\circ}$ & 0 & $\begin{array}{lll}\infty & m \\
0 & 0 & 0 \\
0 & 0\end{array}$ & $\frac{\pi}{\pi}$ & $\stackrel{\infty}{\phi}$ & $\begin{array}{l}\infty \\
\varphi \\
\varphi \\
\varphi\end{array}$ & $\stackrel{m}{m}$ & $\begin{array}{l} \pm \\
\stackrel{t}{+}\end{array}$ & 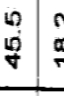 & \begin{tabular}{c} 
N \\
\hdashline \\
\end{tabular} & \begin{tabular}{c|c}
0 \\
0
\end{tabular} & $\hat{N}$ & 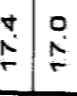 & $\stackrel{\leftrightarrow}{\stackrel{n}{\sim}}$ & $\begin{array}{l}0 \\
0 \\
0\end{array}$ & \begin{tabular}{ll}
$\bullet$ & - \\
\hdashline & $\bar{N}$ \\
\end{tabular} & $\begin{array}{ll}0 \\
0 \\
0\end{array}$ & $0 \mid \begin{array}{l}0 \\
0 \\
0 \\
0\end{array}$ & 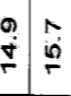 & R & 0 & क़ी \\
\hline & & 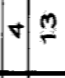 & 0 & $\nabla$ & $m$ & $\tau$ & 0 & ص & $\nabla$ & -7 & - & $\infty$ & - & 0 & $\sigma \nabla$ & +0 & $0 \%$ & $F$ & $=0$ & 0 & 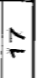 \\
\hline $\begin{array}{l}\frac{6}{8} \\
\frac{9}{6} \\
\frac{9}{9}\end{array}$ & 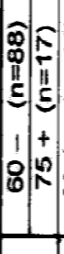 & 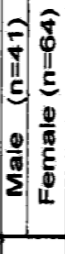 & 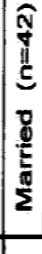 & $\begin{array}{l}5 \\
\bar{f} \\
1 \\
5 \\
3 \\
0 \\
0 \\
3\end{array}$ & $\begin{array}{l}\frac{\sigma}{0} \\
\frac{1}{11} \\
\frac{5}{0} \\
\frac{0}{0} \\
\frac{c}{\omega}\end{array}$ & 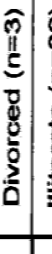 & 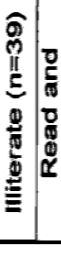 & 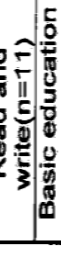 & 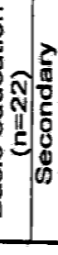 & 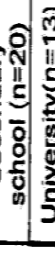 & 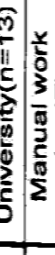 & $\left\{\begin{array}{l}0 \\
5 \\
0 \\
\frac{0}{0}\end{array}\right.$ & 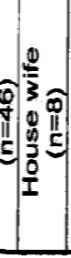 & 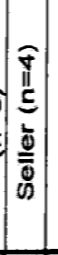 & 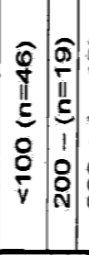 & $\begin{array}{c}0 \\
\vdots \\
0 \\
\vdots \\
\vdots \\
\vdots \\
0 \\
0 \\
m\end{array}$ & 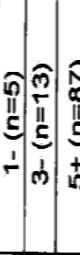 & 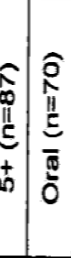 & 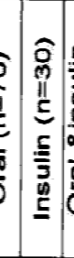 & 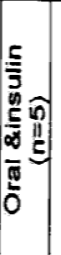 & \\
\hline$\frac{5}{0}$ & 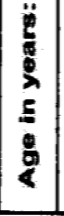 & $\ddot{x}$ & & $\frac{5}{5}$ & & & & 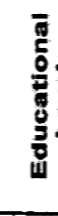 & & & & 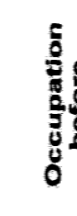 & : & & 造 & & 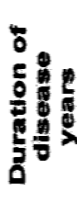 & & 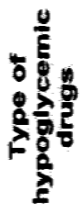 & & 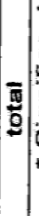 \\
\hline
\end{tabular}




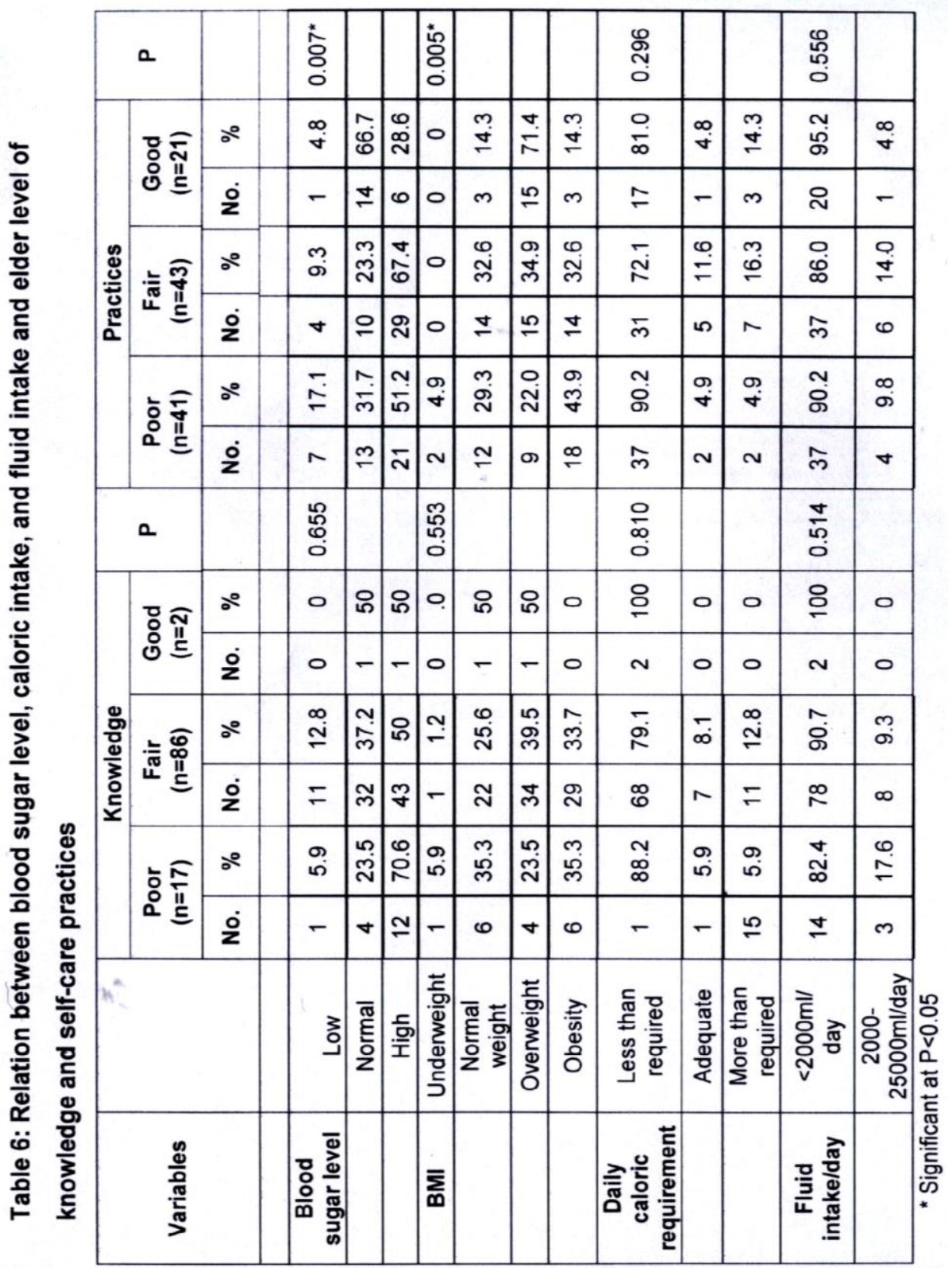




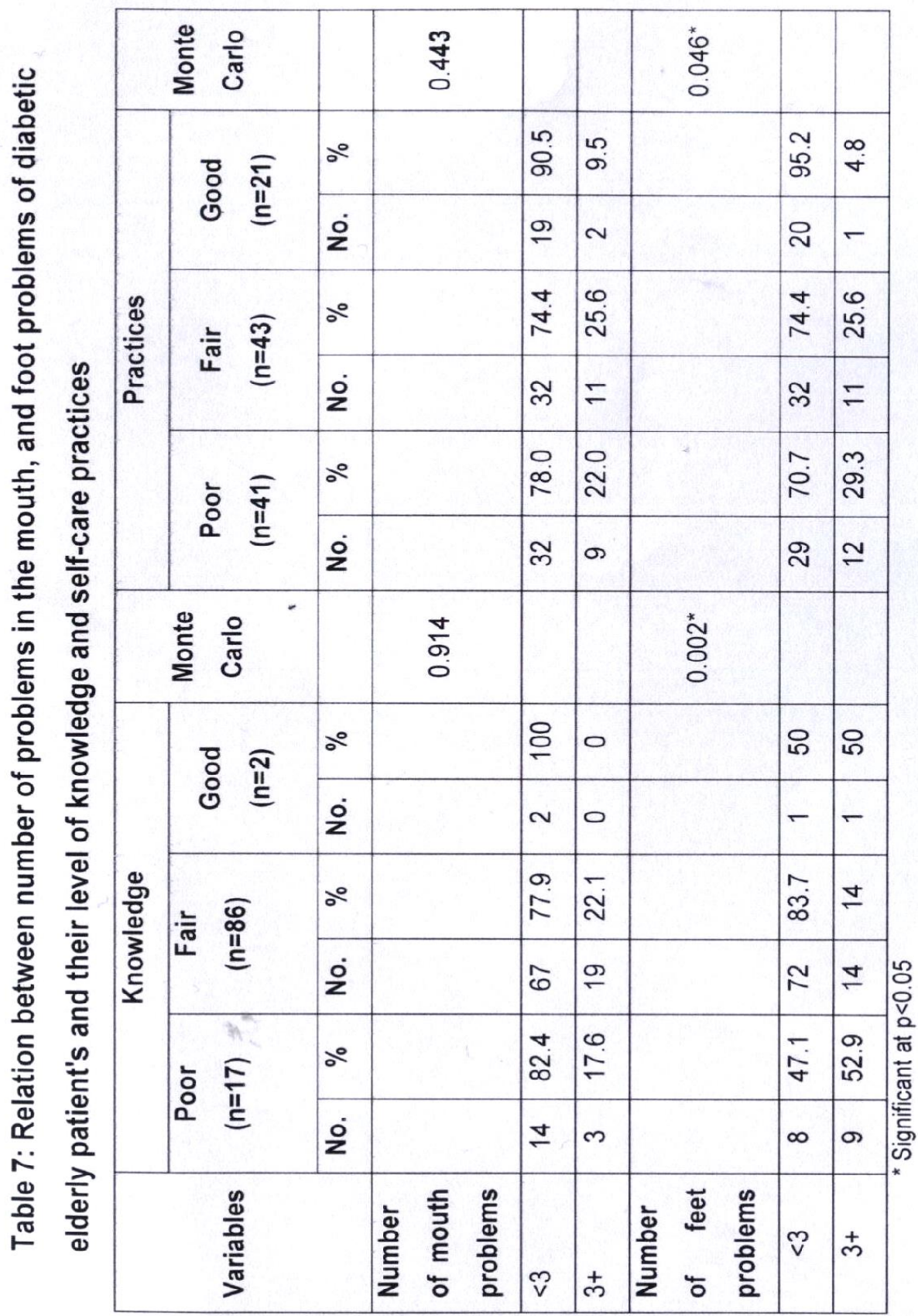




\section{REFERENCEES}

1- Landefeld $C$, Palmer $R$, Johnson $M$, Johnstn B, Lyons W. Current Geriatric Diagnosis and Treatment Intervention $.1^{\text {st }}$ ed., Boston: M C Graw-Hill Co; 2004. 338-347

2- Hassan S. Self-care Practice Among Home Based Diabetic Elderly In Dakahlia Governorate. Thesis, Master Degree .Alexandria: University of Alexandria, Faculty of Nursing, 2005.

3- Kamel NM, Badawy YA, El-Zeiny NA, Merdanl. A. Socio-demographic determinants of management behavior of diabetic patients Part II. Diabetes Knowledge of the disease and their management behavior. Eastern Mediterranean Health Journal. 1999; 5(5): 974-83.

4- El-Sayed E. Development of Visual Educational Materials For Low-Literate Adult Diabetics. Thesis, Master Degree .Alexandria: University of Alexandria, Faculty of Nursing, 1999.

5- Rice R. Home Care Nursing Practice. $3^{\text {rd }}$ ed., St. Louis: Mosby Col 2001. 265277.

6- Ebersole, HL. Toward Healthy Aging: Human Needs and Nursing Response. $6^{\text {th }}$ ed., Mosby Co; 2004. 220-223.

7- Guideline for the Management and care of Diabetes Mellitus, 2008; www. Emro. Who. Int/dsaf/dsa698.

8- Moordian A., Melaughlin S., Boyer C. Diabetes care for older adults. Diabetes Spectrum. 1999; 12(2):70-6.

9- Sdeman W, Sdeman T. Instructions for Geriatric Patients. $3^{\text {rd }}$ ed. Philadelphia: EISevier Saunders Co; 2005.333-3335

10- Living with diabetes. 3 June, 2001 (C) Diabetes Insight webmaster@diabetes-insight.info

11- Shafic H. Medication Compliance Among Institutionalized Elderly. Thesis, Master Degree .Alexandria: University of Alexandria, Faculty of Nursing, 2000.
12- Bedier N. An Instructional scheme for non-hospitalized elderly patients, Based on Identification Patterns of Compliance to Their Prescribed Medications. Thesis, MD. Alexandria: University of Alexandria, Higher Institute of Nursing, 1987.

13- .Pardya N. Diabetes Management in Long Care. Caring For the Ages. 2003; 4 (2) 222-5.

14- Thompson J. Psychological Features characterizing Oral health Behavior, Diabetes Self-Care Health Status Among IDDM Patients. www.diabetes self-care.com

15- Cotter V, Strumpf N. Advanced Practice Nursing with Older Adults: clinical guidelines. New York: MC Graw-Hill Co; 2002. 103-24

16- Anastasi M. Management of Diabetes Mellitus in Adults www.humana.com/providers/guidelines/ intro.asp.

17- Eliopoulos C. Gerontological Nursing. $5^{\text {th }}$ ed. Philadelphia: Lippncott Co; 2001. 75-78.

18- Hallaj F. Activity Patterns of Residents in Elderly homes. Thesis, Master Degree .Alexandria: University of Alexandria, Faculty of Nursing, 2007.

19- EL-Gameel M. Study of Fall Among Institutionalized Elderly in Alexandria.Thesis, Master Degree. Alexandria: University of Alexandria, Faculty of Nursing. 2001

20- Mahfouz M. Quality of life for institutionalized elders. Thesis, Master Degree. Alexandria: University of Alexandria, Faculty of Nursing, 2005.

21-Amer W, Moussa E, Hashem E. Calcium and Phosphorus Concentration in Gingival Tissue and Sera in Insulin Dependent Diabetic Patients. The Egyptian Journal of Diabetes. 1996; 1(2): 78-85. 
22- Heggy E. Assessment of Self-Care Practices Among Adult Diabetic Patients. Thesis, MD. University of Alexandria, Faculty of Nursing, 2001.

23- Abd El-Rehim A. Education for Foot Care. The Egyptian Journal Of Diabetes. 1996; 1(1): 44-6.

24- Eweda S, Ahmed N, Abd El-Wahab T. Comparative Study to Determine The Effectiveness of Utilization of Different Dressing Techniques and Solution in Dressing of Septic Diabetic foot Ulcers. Journal of the Medical Research Institute. 1994; 15(1): 44-52.
25- Thomas, Al-Kendan F. Health Promoting Life Style and Body Mass Index Among College Of Nursing Students In Kuweat: A Correlational Study. Nursing and Health Science 2008;10(1): 43-50.

26- Duff EM, O'connor A, Anderson M, Wint YB, Bailay EY, Pascoe W. Self-Care, Compliance and Glycemic Control In India Adults With Diabetes Mellitus. West India Medical Journal. 2006; 55(4). 
